\title{
Clinical Characteristics and Gender Differences in Suicide Attempters: A Hospital-based Cross-sectional Study
}

\author{
Akansha Jain ${ }^{1}$, Narayan R Mutalik ${ }^{2}$
}

\begin{abstract}
Background: Even though attempted suicides represent the "tip of the iceberg," they are slowly assuming the levels of a public health problem caused by several factors. We aimed to study the various clinical characteristics and gender differences among suicidal attempters.

Methods: A hospital-based cross-sectional study was conducted after taking ethical clearance. Data were collected from a tertiary care center at Bagalkot over the 6 months. The subjects who fulfilled the inclusion and exclusion criteria were evaluated by using semistructured pro forma, and various scales like Beck's Depression Inventory (BDI), Beck's Anxiety Inventory (BAI), and Beck's Suicide Intent Scale (SIS) were applied. Relevant statistical tests were performed.

Results: Total number of study participants was 100 out of which $52 \%$ were females and $48 \%$ were males. The mean age of suicide attempters was 29.08 ( $S D=11.601$ ). Organophosphorus poisoning was the mode of attempt in $33 \%$ of the study subjects and $26 \%$ had severe depression. Conclusion: Factors responsible for attempted suicides were young adults, female sex, low socioeconomic status, low education level, with marriage also being a potential one. Depression and anxiety are the psychiatric disorders associated strongly with a suicide attempt. Most of these factors can be either prevented or controlled.

Keywords: Anxiety, Depression, Suicide, Suicide attempt.

Indian Journal of Private Psychiatry (2021): 10.5005/jp-journals-10067-0081
\end{abstract}

\section{INTRODUCTION}

Suicidal attempts are common problems, encountered in psychiatric clinics, and have become a cause of concern. "Attempted suicide is a self-injurious action with nonfatal outcome but with evidence suggestive enough of a person intended to kill oneself." ${ }^{1}$ Suicide forms a major proportion of premature death globally. Every year, more than 8,00,000 end their lives and many more try to end their lives. ${ }^{2}$ It is a global phenomenon. It is the second leading cause of death among the age-group of $15-29$ years. ${ }^{3}$ Seventy-five percent of the suicides occur in low- and middle-income countries in $2012 .^{4}$

According to the National Crime Records Bureau data, an increase in suicide numbers from 110,851 in 2003 to 134,799 in 2013 has been recorded accounting $21.6 \%$ increase during the decade ${ }^{5}$ with the suicide rate being 18.5 per 1 lakh population in Karnataka in the year $2013 .{ }^{5}$ Suicide is a single problem influenced by multidimensional determinants. Sociodemographic characteristics along with clinical problems together form the major cause of suicidal attempts. Globally, suicidal attempts are more prevalent in women, whereas death by suicide is more common in men. ${ }^{2}$ People below 30 years are more vulnerable to commit suicide in India. ${ }^{6,7}$ Pesticide consumption is the most common method to commit suicide. ${ }^{8}$ The biggest problem faced in India is that behind one suicide, a large number of people tend to end their lives, making suicidal attempts a major risk factor for suicide in the population. This indicates the need to thoroughly examine patients with a history of suicide attempts to prevent further harmful consequences. Taking all these into considerations, this study was planned to assess the various sociodemographic factors, clinical characteristics in suicide
1,2 Department of Psychiatry, S Nijalingappa Medical College and HSK Hospital, Bagalkot, Karnataka, India

Corresponding Author: Narayan R Mutalik, Department of Psychiatry, S Nijalingappa Medical College and HSK Hospital, Bagalkot, Karnataka, India, Phone: +91 9901621771, e-mail: drnrmutalik@hotmail.com

How to cite this article: Jain A, Mutalik NR. Clinical Characteristics and Gender Differences in Suicide Attempters: A Hospital-based Crosssectional Study. Ind J Priv Psychiatry 2021;15(1):32-37.

Source of support: Nil

Conflict of interest: None

attempters, and also to know the gender differences in patients with a history of suicide attempts.

The aims and objectives of the study were the following:

- To assess various demographic and clinical characteristics in patients with a history of the suicide attempt.

- To understand the gender differences in suicide attempters.

- To know the association of depression, anxiety, and suicide intent with a suicide attempt.

\section{Materials and Methods}

This prospective case series study was conducted among the patients with the history of suicide attempt admitted to a tertiary care hospital at Bagalkot over a period of 6 months from October 2018 till March 2019. A convenient sample size of 100 was considered for the study. The Institute's Ethics Committee (Human Studies) had granted the ethical clearance. Before enrollment in the study, all study subjects had given the written informed consent in the local language.

(c) The Author(s). 2021 Open Access This article is distributed under the terms of the Creative Commons Attribution 4.0 International License (https://creativecommons. org/licenses/by-nc/4.0/), which permits unrestricted use, distribution, and non-commercial reproduction in any medium, provided you give appropriate credit to the original author(s) and the source, provide a link to the Creative Commons license, and indicate if changes were made. The Creative Commons Public Domain Dedication waiver (http://creativecommons.org/publicdomain/zero/1.0/) applies to the data made available in this article, unless otherwise stated. 


\section{Inclusion Criteria}

The inclusion criteria applied in the case study are as follows:

- All age-groups with a history of suicide attempt within 1 month of the evaluation.

- Patients willing to participate in the study and give informed consent for the study.

\section{Exclusion Criteria}

The following factors are the exclusion criteria considered in this study:

- Patients with organic brain syndrome (delirium and dementia) and organic mental disorders like head injury, tumors, and CNS infections, and mental retardation.

- Patients with intellectual disabilities.

- Patients admitted to intensive care units who are on artificial respiration.

The study population was recruited after considering the inclusion-exclusion criteria. The nature and the purpose of the study were explained to the study population as in the informed consent form. During the investigation time frame, every one of the participants was given standardized self-answering questionnaires as referenced underneath in the instruments utilized. Once the questionnaires were collected, the sample was subjected to statistical analysis.

\section{Instruments Used}

- Especially designed pro forma: This is to elicit information on several aspects of the participants' background: age, gender, education, occupation, residential background, personal history of mental illness or on any medications, family history of psychiatric disorders, psychosocial stress factors, and the details related to the suicide attempt.

- Beck's Suicide Intent Scale: It is a 20-item clinical research instrument designed to record information regarding the intensity of the suicide attempters' wishes to die at the time of the attempt. It must be completed by a clinician during the course of a structured interview. The scale was comprised of two sections: the first section being objective, and the second section, evaluating the subjective characteristics of the suicide attempt. The first nine items deal with circumstances related to suicide attempts. Items from numbers $10-15$ assess patient reports of thoughts and feelings at the time of the attempt. Items from numbers 16-20 describe other aspects of the suicide attempt (like the number of previous attempts, a person's reaction to the attempt, and the consumption of alcohol or drugs at the time of the attempt). Suicide intent scale scores obtained are classified as follows: 15-19 points "low-intent," 20-28 points "medium-intent," and $>29$ points "high-intent" suicides. ${ }^{9}$

- Beck's Depression Inventory-II: It is a self-completed questionnaire with 21 items in a multiple-choice format. For every item, there will be four statements and the subjects were given the instructions to select an item that best described their condition during the last 2 weeks. Each of the statements was rated between 0 and 3 , where 0 is considered normal or least depressed mood and 3 is considered as the most depressed mood. A total score of Beck's Depression Inventory (BDI) was obtained by the addition of all the values. The score was also divided into two subscales, BDI 1-13 and BDI 14-21, for cognitive-affective and somatic-vegetative symptoms. Studies have supported the reliability and validity of the BDI-II in clinical samples. ${ }^{10}$

- Beck's Anxiety Inventory: It is a 21-item multiple-choice self-report inventory that measures the severity of anxiety in adults and adolescents. Beck's Anxiety Inventory (BAI) can differentiate anxiety from depression on the grounds that the things in the BAI portray the emotional, physiological, and cognitive symptoms of anxiety but not depression. The total BAI score was obtained by adding all the items. The total score from 0-21 amounts to low anxiety, from 22-35 amounts to moderate anxiety, and 36 and above is termed potentially concerning levels of anxiety. ${ }^{11}$

\section{Statistical Analysis}

Statistical analyses of the data were performed using IBM SPSS Statistics for Windows (trial version 20.0). Frequency and percentages were calculated for all qualitative measures. Quantitative measures were analyzed using mean and standard deviation. Chi-square test and Fisher's exact test were used to analyze categorical values and check the association between two variables. A $p$-value of $<0.05$ is considered statistically significant.

\section{Results}

It is a hospital-based study with a sample size of 100 . The age of the participants was in the range of 16-72 years with a mean age of suicide attempters being 29.08 (SD = 11.601) (Fig. 1). Out of $100,52 \%$ were females and $48 \%$ were males among whom $67 \%$ of the cases were brought to the hospital by the family members themselves and the rest were referred by the physician (Table 1). None of the study subjects had any family history of psychiatric disorders. Thirty-three percent of the subjects attempted suicide by organophosphorus poisoning followed by lice powder consumption in $18 \%$ of the study participants (Fig. 2). Five subjects had a past and current history of taking psychotropic medication and $15 \%$ of the participants were suffering from one or other medical illnesses. Ninety-five percentage of the cases did not have any past history of suicide attempts and two subjects had attempted three or more times. Twenty-six percent of the subjects had severe depression, whereas only $10 \%$ of them had anxiety which was a potential cause of concern (Fig. 3). A Chi-square test was performed to examine the relation between the variables like

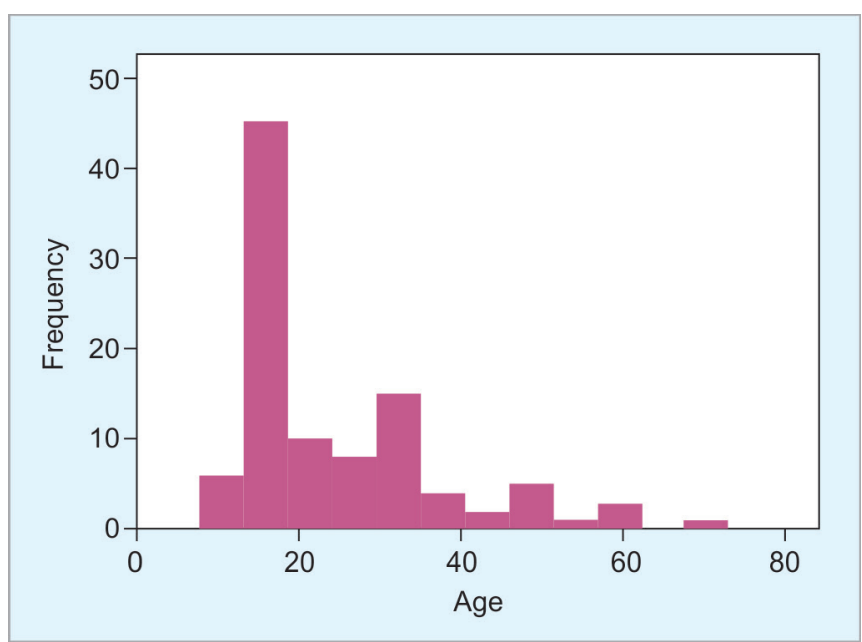

Fig. 1: Distribution of age of subjects 
Table 1: Demographic details of study participants

\begin{tabular}{llc}
\hline Variables & & Frequency (N=100) \\
\hline Gender & Male & $48 \%$ \\
Socioeconomic status & Female & $52 \%$ \\
& Above poverty line (APL) & $24 \%$ \\
Educational status & Below poverty line & $76 \%$ \\
& Nil/illiterate & $14 \%$ \\
& Primary (1st-5th std) & $11 \%$ \\
& School (6th-10th std) & $30 \%$ \\
& Higher secondary (11th and 12th std) & $20 \%$ \\
Residential background & Graduate & $25 \%$ \\
& Urban & $40 \%$ \\
Occupational status & Rural & $60 \%$ \\
& Unemployed & $5 \%$ \\
& Housewife & $28 \%$ \\
& Farmer/unskilled & $28 \%$ \\
& Semiskilled/skilled & $14 \%$ \\
& Professional & $3 \%$ \\
Marital status & Student & $22 \%$ \\
& Unmarried & $40 \%$ \\
& Married/divorced & $60 \%$ \\
\hline
\end{tabular}

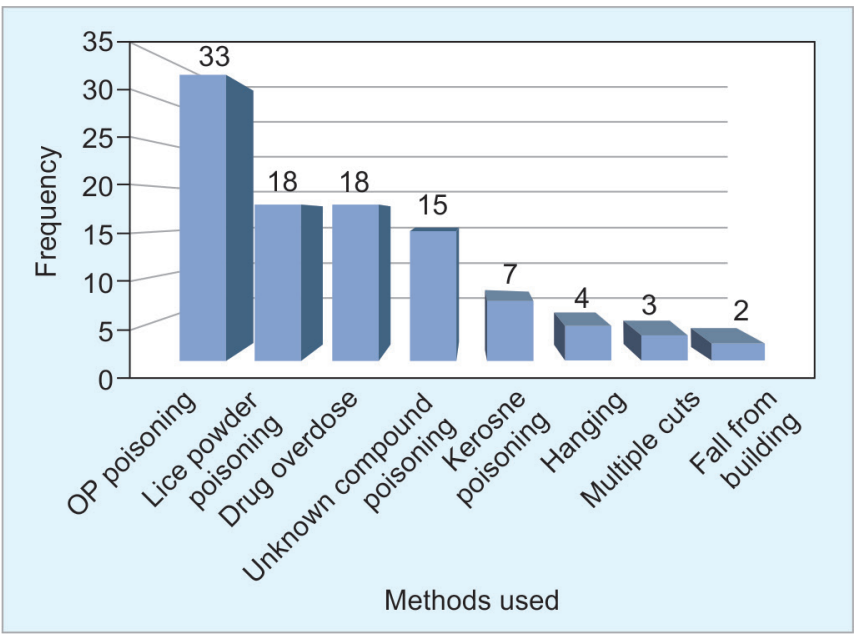

Fig. 2: Methods used to attempt suicide

gender, marital status, residential background, and the severity of depression. We found that females, married/divorced people, subjects from the rural population had severe depression (Table 2). A Chi-square test was performed to examine the relation between gender and severity of anxiety. We found that a greater number of females than males had moderate anxiety. Males more than females had anxiety being a potential cause for concern (Table 3). But we did not find any significant association between socioeconomic status, marital status, and severity of anxiety. The mean scores of $\mathrm{BDI}$ and $\mathrm{BAI}$ were $22.35(\mathrm{SD}=0.83)$, respectively. When we compared differences in gender across BDI and BAI scores, we did not find any statistically significant difference. A Chi-square test was performed to examine the relation between gender and severity of suicide intent. There was no association between the gender of the subject and suicide intent severity $\left\{X^{2}(1)=0.289, p=0.591\right\}$. There was no significant association between the socioeconomic status of the subject and suicide intent severity $\left\{X^{2}(1)=0.767, p=0.381\right\}$. No association was found

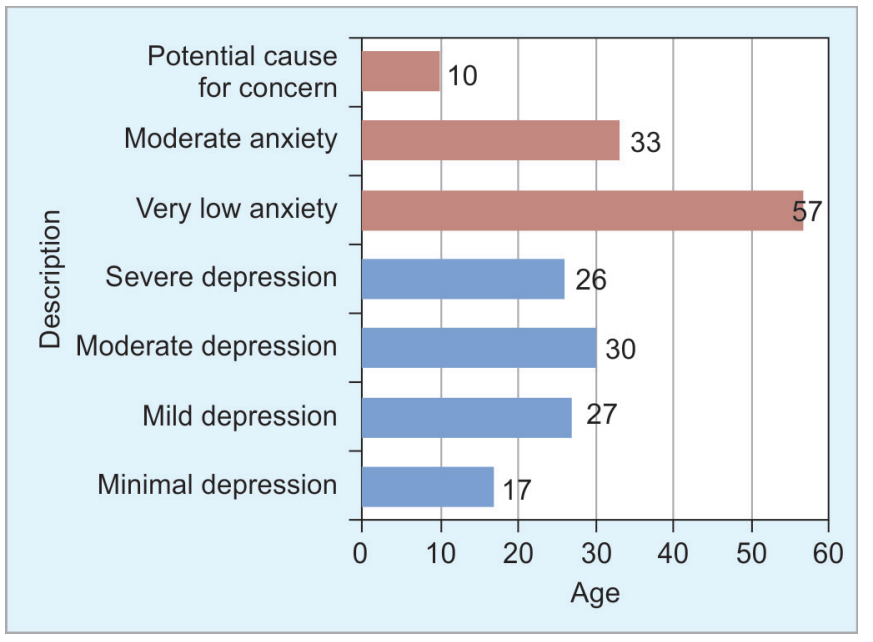

Fig. 3: Severity of anxiety and depression based on BAI and BDI

between marital status and suicide intent severity $\left\{X^{2}(2)=0.735\right.$, $p=0.693\}$. No association was found between residential background and suicide intent severity $\left\{X^{2}(1)=0.028, p=0.868\right\}$. We found no association between the history of medical illness and suicide intent severity $\left\{X^{2}(1)=1.110, p=0.292\right\}$ (Table 4).

\section{Discussion}

Through this study, we tried to find out the clinical characteristics and gender differences and their association with depression, anxiety, and suicide intent in suicide attempters. Peak occurrence of suicides was observed in the age group of 20-22 years, the youngest and the oldest being 16 and 72 years, respectively. These findings are corroborated by a study by Nukala et al. ${ }^{12}$

These findings confirm that attempted suicides are increasing rapidly among youths. The mean age of patients committing suicide was 29.08 (SD = 11.601). Similar observations were found in the study made by Krishna and Sheikh. ${ }^{13}$ Out of $100,52 \%$ were females 
Table 2: Association of various demographic factors with severity of depression

\begin{tabular}{|c|c|c|c|c|c|c|}
\hline \multirow{2}{*}{\multicolumn{2}{|c|}{ Sociodemographic variables }} & \multicolumn{5}{|c|}{ Severity of depression } \\
\hline & & \multirow{2}{*}{$\frac{\text { Minimal }}{14 \%}$} & \multirow{2}{*}{$\frac{\text { Mild }}{8 \%}$} & \multirow{2}{*}{$\frac{\text { Moderate }}{16 \%}$} & \multirow{2}{*}{$\begin{array}{c}\text { Severe } \\
10 \%\end{array}$} & \multirow{3}{*}{$\begin{array}{c}\text { Test significance } \\
X^{2}(3, N=100)=12.97 \\
p=0.005\end{array}$} \\
\hline Gender & Male & & & & & \\
\hline & Female & $3 \%$ & $19 \%$ & $14 \%$ & $16 \%$ & \\
\hline \multirow[t]{2}{*}{ Marital status } & Unmarried & $3 \%$ & $15 \%$ & $15 \%$ & $7 \%$ & \multirow{2}{*}{$\begin{aligned} X^{2}(3, N & =100)=9.36 \\
p & =0.025\end{aligned}$} \\
\hline & Married/divorced & $14 \%$ & $12 \%$ & $15 \%$ & $19 \%$ & \\
\hline \multirow[t]{2}{*}{ Residence } & Urban & $2 \%$ & $11 \%$ & $20 \%$ & $7 \%$ & \multirow{2}{*}{$\begin{array}{c}X^{2}(3, N=100)=16.39 \\
p=0.001\end{array}$} \\
\hline & Rural & $15 \%$ & $16 \%$ & $10 \%$ & $19 \%$ & \\
\hline \multirow[t]{2}{*}{ Medical comorbidity } & Yes & $2 \%$ & $2 \%$ & $5 \%$ & $6 \%$ & \multirow{2}{*}{$\begin{aligned} X^{2}(3, N & =100)=2.75 \\
p & =0.431\end{aligned}$} \\
\hline & No & $15 \%$ & $25 \%$ & $25 \%$ & $20 \%$ & \\
\hline
\end{tabular}

Table 3: Association of various demographic factors with severity of anxiety

\begin{tabular}{llcccc}
\hline & & \multicolumn{3}{c}{ Severity of anxiety } \\
\cline { 2 - 5 } Sociodemographic variables & Very low anxiety & Moderate anxiety & Potential cause of concern & Test significance \\
\hline Gender & Male & $33 \%$ & $9 \%$ & $6 \%$ & $X^{2}(2, N=100)=8.493$ \\
& Female & $24 \%$ & $24 \%$ & $4 \%$ & $p=0.014$ \\
Socioeconomic status & APL & $14 \%$ & $8 \%$ & $2 \%$ & $X^{2}(2, N=100)=0.099$ \\
& BPL & $43 \%$ & $25 \%$ & $8 \%$ & $p=0.952$ \\
Marital status & Unmarried & $23 \%$ & $14 \%$ & $3 \%$ & $X^{2}(3, N=100)=0.500$ \\
& Married/divorced & $34 \%$ & $19 \%$ & $7 \%$ & $p=0.779$ \\
Residence & Urban & $23 \%$ & $15 \%$ & $2 \%$ & $X^{2}(3, N=100)=2.079$ \\
& Rural & $34 \%$ & $18 \%$ & $8 \%$ & $p=0.354$ \\
Medical comorbidity & Yes & $5 \%$ & $7 \%$ & $3 \%$ & $X^{2}(3, N=100)=4.498$ \\
& No & $52 \%$ & $26 \%$ & $7 \%$ & $p=0.106$ \\
\hline
\end{tabular}

Table 4: Association of various demographic factors with suicide intent severity

\begin{tabular}{llccc}
\hline \multirow{2}{*}{ Sociodemographic variables } & & \multicolumn{3}{c}{ Suicide intent severity } \\
\cline { 2 - 4 } Gender & Male & $27 \%$ & $21 \%$ & $X^{2}(1, N=100)=0.289$, \\
& Female & $32 \%$ & $20 \%$ & $p=0.591$ \\
Socioeconomic status & APL & $16 \%$ & $8 \%$ & $X^{2}(1, N=100)=0.767$, \\
Marital status & BPL & $43 \%$ & $33 \%$ & $p=0.381$ \\
& Single & $23 \%$ & $17 \%$ & $X^{2}(2, N=100)=0.735$, \\
Residence & Married & $35 \%$ & $24 \%$ & $p=0.693$ \\
\multirow{5}{*}{ History of medical illness } & Divorced & $1 \%$ & $0 \%$ & \\
& Urban & $24 \%$ & $16 \%$ & $X^{2}(1, N=100)=0.028$, \\
& Rural & $35 \%$ & $25 \%$ & $p=0.868$ \\
& Yes & $7 \%$ & $8 \%$ & $X^{2}(1, N=100)=1.110$, \\
& No & $52 \%$ & $33 \%$ & $p=0.292$ \\
\hline
\end{tabular}

and $48 \%$ were males, similar results were found in the previous studies. ${ }^{14,20}$ On the contrary, male preponderance was seen in studies by Kodali and Kilaru. ${ }^{16,17,19}$ Most of the suicide attempters (76\%) belonged to the below poverty line (BPL) $(76 \%)$ and rural areas (60\%), in accordance with the study made by Krishna and Sheikh. ${ }^{13}$ Most of the subjects in our study (55\%) were educated only up to 10th standard which is corroborated by a study where a low educational status was found among $21 \%$ of the individuals and authors were of the opinion that it may have influenced the help-seeking and decision-making which could be an important risk factor for suicide attempt. ${ }^{21}$ Farmers (28\%) and housewives (28\%) form the major group of the subjects attempting suicide similar to a study by Baalasubramanian et al. ${ }^{22}$ and Nukala et al. ${ }^{12}$ The reason for farmers attempting suicide might be the agricultural background and rural population in the study and the socioeconomic issues faced by them in the developing world. Attempted suicides were more in married (60\%) than in unmarried, similar to a study by Kodali and Kilaru ${ }^{19}$ suggesting marriage to be a less protective factor for females in suicide against males of the same age. Marriage is a strong cultural practice and a major social obligation in India, most of the deliberate self-harm patients were found to be married, which was similar to the findings of other Indian studies. ${ }^{17,18}$ 
The World Health Organization (WHO) reports that widowed, single, and divorced individuals are at a greater risk of attempting suicide than the married people. The cited reason was that marriage in India is a social commitment, which is performed by the elderly folks, regardless of the person's readiness for it. Conjugal accomplices in India are basically aliens to one another (because of arranged marriages) as are the families. So, a few relationship issues could emerge among the wedded people.

The most common method of suicidal attempts was poisoning which was similar to various other studies. ${ }^{15,23,24}$

In our study, most of the patients were suffering from psychiatric disorders $30 \%$ of them suffering from moderate depression. Similar findings were reported in the previous studies by Chandrasekaran et al., ${ }^{14}$ and Kodali and Kilaru, ${ }^{19}$ Bansal and Barman, ${ }^{23}$ and Das et al. ${ }^{25}$

Anxiety is not a causative factor for suicidal attempts in our study as $57 \%$ of the subjects have very low anxiety. On the contrary, the study by Sareen et al. suggests that anxiety plays a major role in suicidal attempts as the majority of the cases had at least one anxiety disorder in their study. ${ }^{26}$ Our study did not show any significant relation between the suicidal intent and the attempted suicide which was calculated by using Beck's Suicide Intent Scale. On the contrary, a study conducted by Harriss et al. showed a significant relation between the variables. ${ }^{27}$

The result showing the association between the suicidal intent and depression was significant with $30 \%$ of the patients diagnosed with moderate depression. Similar results were found in the study conducted by Suominen et al. where results were significant. ${ }^{28}$ The association between the suicidal intent and anxiety was insignificant in our study as $57 \%$ of the subjects did not suffer from anxiety or any other anxiety disorders. Similar findings were reported by a study conducted by Placidi et al. ${ }^{29}$

The main limitation of this study is that it is a hospital-based cross-sectional study. Due to the social stigma associated with psychiatric disorders and suicidal attempts, people reporting to the hospital are far less than the actual count representing the tip of the iceberg of the actual problem prevalent in the society. The legislative measures taken against them on reporting further add to the problem of underreporting. The study also represents only a small population of the society so generalized results for a population cannot be interpreted through the study. More researches should be done on suicidal attempts concerning the limitations in the present study to know the actual scenario of the problem in the society. Community-based longitudinal studies are the need of the hour to reveal some more factors by avoiding the selection bias.

\section{Conclusion}

Suicidal attempts are the most serious issue of concern in the present world. Female preponderance, young adults are generally the target. A low socioeconomic group of rural backgrounds forms the major risk factor. Married young females are more prone to depression leading to suicidal attempts. Anxious people have less suicidal intent than the normal population. Pesticide and lice powder consumption is the most common method of suicidal attempt. The reason behind this could be the easy availability and agricultural background of the area. Suicide prevention is a multidisciplinary approach. Programs for suicide prevention should be implemented for the population at risk. Every year September 10 is observed as World Suicide Prevention Day to provide worldwide commitment and action to prevent suicides. Most of these factors can be either prevented or controlled. Early identification of suicideprone individuals is the need of the hour so as to prevent and control suicides effectively.

\section{ACKNOWLEDgments}

Author's acknowledge the immense help from the scholars and authors of the articles cited. We would like to thank all the patients who became the part of the study. We are also grateful to the publishers and authors of the journals, books, from where the literature has been reviewed. We are thankful to our hospital authorities for permitting us to conduct this study.

\section{References}

1. Rathi PS. Psycho-social assessment of patients in ICU with deliberate self harm: an observational study. Int Med J 2016;3(1):20-23. Available from: https://www.medpulse.in/Article/Volume3lssue1/ MedPulse_3_1_6.pdf"

2. Kumar KK, Sattar FA, Bondade S, et al. A gender-specific analysis of suicide methods in deliberate self-harm. Indian J Soc Psychiatry 2017;33(1):7. DOI: 10.4103/0971-9962.200098.

3. World Health Organization. 2016. Suicide data. Available from: http://www.who.int/mental_health/prevention/suicide/ suicideprevent/en/

4. WHO. Suicide 2015. Fact Sheet No. 398; 2015. Available from: http:// www.who.int/mediacentre/factsheets/fs398/en/

5. National Crimes Records Bureau. Accidental deaths and suicides in India 2013. New Delhi: Ministry of Home Affairs, Government of India; 2014.

6. Reddy MS. Suicide incidence and epidemiology. Indian J Psychol Med 2010;32(2):77. DOI: 10.4103/0253-7176.78501.

7. Vijayakumar L. Indian research on suicide. Indian J Psychiatry 2010;52(Suppl. 1):S291. DOI: 10.4103/0019-5545.69255.

8. Suresh Kumar PN. An analysis of suicide attempters versus completers in kerala. Indian J Psychiatry. 2004 Apr;46(2):144-149. PMID: 21408041; PMCID: PMC2949930.

9. Beck AT, Kovacs M, Weissman A. Assessment of suicidal intention: the scale for suicide ideation. J Consult Clin Psychol 1979;47(2):343-352. DOI: 10.1037//0022-006x.47.2.343.

10. Beck AT, Steer RA, Brown GK. BDI-II manual. San Antonio, TX: Harcourt Brace \& Company; 1996.

11. Beck AT, Epstein N, Brown G, et al. An inventory for measuring clinical anxiety: psychometric properties. J Consult Clin Psychol 1988;56(6);893-897. DOI: 10.1037//0022-006x.56.6.893.

12. Nukala S, Edam R, Dattatrey M. Psychiatric morbidity in patients of attempted suicide admitted in a rural area hospital of northern Andhra Pradesh. Int J Cur Res Rev 2013;5(21):65-70. DOI: 10.31782/ IJCRR.2013.111313.

13. Krishna VM, Sheikh NA. Psychiatric co-morbidity in deliberate self harm patient at rural medical college of South India. Int J Rec Adv Multidiscip Res 2014;1(12):119-123.

14. Chandrasekaran R, Gnanaseelan J, Sahai A, Swaminathan RP, Perme $B$. Psychiatric and personality disorders in survivors following their first suicide attempt. Indian J Psychiatry. 2003 Apr;45(2):45-48. PMID: $21206833 ;$ PMCID: PMC2952146.

15. Latha KS, Bhat SM, D'souza P. Suicide attempters in a general hospital unit in India: their socio-demographic and clinical profile, emphasis on cross-cultural aspects. Acta Psychiatr Scand 1996;94(1):26-30. DOI: 10.1111/j.1600-0447.1996.tb09820.x.

16. Narang RL, Mishra BP, Nitesh $M$. Attempted suicide in Ludhiana. Indian J Psychiatry. 2000 Jan;42(1):83-87. PMID: 21407914; PMCID: PMC2957009.

17. Kumar PN. Age and gender related analysis of psychosocial factors in attempted suicide. Indian J Psychiatry. 1998 Oct;40(4):338-345. PMID: 21494498; PMCID: PMC2966685. 
18. International Institute for Population Sciences (IIPS) and Macro International 2007. National family Health Survey (NFHS-3): Vol 1. India: Mumbai: IIPS; 2005-06.

19. Kodali M, Kilaru K. Psychiatric morbidity of attempted suicide patients admitted to a general hospital in rural area of South India. J Dent Med Sci 2008;4(3):46-50. DOI: 10.9790/0853-0434650.

20. Kessler RC, Borges G, Walters EE. Prevalence of and risk factors for lifetime suicide attempts in the National Co-morbidity Survey. Arch Gen Psychiatry 1999;56(7):617-626. DOI: 10.1001/archpsyc.56.7.617.

21. Sudhir Kumar CT, Mohan R, Ranjith G, et al. Gender differences in medically serious suicide attempts: a study from south India. Psychiatry Res 2006;144(1):79-86. DOI: 10.1016/j.psychres. 2005.11.012.

22. Baalasubramanian S, Pradeep ANKS, Jayaraman $S$, et al. Sociodemographic risk factors among deliberate self-harm in young women with tertiary care. Int J Curr Med Pharmaceut Res 2016;2(11):1036-1039.

23. Bansal PD, Barman R. Psychiatric morbidity and the sociodemographic determinants of deliberate self harm. J Clin Diagn Res 2011;5(3):601-604. DOI: JCDR/2011/1326.
24. Kiran Kumar PK, Sukesh S, Kakunje A, et al. Epidemiology of psychiatric disorders in deliberate self harm victims. J Evol Med Dent Sci 2013;2(7):738-744. DOI: 10.14260/jemds/333.

25. Das PP, Grover S, Avasthi A, et al. Intentional self-harm seen in psychiatric referrals in a tertiary care hospital. Indian J Psychiatry 2008;50(3):187. DOI: 10.4103/0019-5545.43633.

26. Sareen J, Cox BJ, Afifi TO, et al. Anxiety disorders and risk for suicidal ideation and suicide attempts: a population-based longitudinal study of adults. Arch Gen Psychiatry 2005;62(11):1249-1257. DOI: 10.1001/ archpsyc.62.11.1249.

27. Harriss $L$, Hawton $K$. Suicidal intent in deliberate self-harm and the risk of suicide: the predictive power of the Suicide Intent Scale. J Affect Disord 2005;86(2-3):225-233. DOI: 10.1016/j.jad.2005.02.009.

28. Suominen K, Isometsä $E$, Henriksson $M$, et al. Hopelessness, impulsiveness and intent among suicide attempters with major depression, alcohol dependence, or both. Acta Psychiatr Scand 1997;96(2):142-149. DOI: 10.1111/j.1600-0447.1997.tb09919.x.

29. Placidi GP, Oquendo MA, Malone KM, et al. Anxiety in major depression: relationship to suicide attempts. Am J Psychiatry 2000;157(10):1614-1618. DOI: 10.1176/appi.ajp.157.10.1614. 